\title{
A Case of Motor Neuron Disease Presenting as Dyspnea in the Emergency Department

\author{
Hyun Soo Park*
}

Department of Emergency Medicine, Dankook University College of Medicine, Cheonan, Korea

\begin{abstract}
Motor neuron disease encompasses a group of progressive neurologic disorders that destroy cells responsible for the control of essential muscles. The disorders are characterized by progressive weakness, muscle atrophy and fasciculation, spasticity, dysarthria, dysphagia, and respiratory compromise. A 66-year-old male presented to the emergency department with progressive dyspnea and, ultimately, respiratory failure. In spite of extensive cardiopulmonary evaluation, a cause could not be identified except aging. After complete history taking, physical and neurologic examination, motor neuron disease was suspected at last. Thus, elderly patients with dyspnea in the emergency department could have hidden diseases beyond the normal aging process.
\end{abstract}

Keywords: Motor Neuron Disease; Amyotrophic Lateral Sclerosis; Dyspnea

\section{INTRODUCTION}

Motor neuron disease (MND) is a heterogenous group of disorders those selectively affect upper or lower motor neurons, or both. Sporadic amyotrophic lateral sclerosis (ALS) accounts for approximately $80 \%$ of all cases of acquired motor neuron disease, whereas the remaining $20 \%$ of patients have either only lower motor neuron signs or a familial form of ALS (FALS). The $80 \%$ of patients who have sporadic ALS present with spasticity, hyperreflexia, and Babinski's sign in the setting of progressive

Received: January 31, 2012, Accepted: March 15, 2012

${ }^{*}$ Corresponding Author: Hyun Soo Park

Tel: 82-41-550-6865, Fax: 82-41-550-7054

E-mail:phs0331@gmail.com

Korean Journal of Family Medicine

Copyright (C) 2012 The Korean Academy of Family Medicine (a) This is an open-access article distributed under the terms of the Creative Commons Attribution Non-Commercial License (http://creativecommons.org/licenses/by-nc/3.0) which permits unrestricted noncommercial use, distribution, and reproduction in any medium, provided the original work is properly cited. muscle wasting and weakness. ${ }^{1)}$ Although symptoms may originate in one region, they will typically spread to involve other areas. After several years, most patients require help with activities of daily living. Weakness of respiratory muscles is common and is the presenting symptom in rare cases in ALS. Early in ALS, individuals complain of dyspnea with exertion and frequently sigh at rest. With disease progression, dyspnea at rest, inability to sleep in a supine position, sleep apnea, and morning headaches are present. ${ }^{1)}$ In the elderly, other more common diagnoses associated with the aging process, such as heart failure, aspiration pneumonia, and dementia, can delay the diagnosis of MND. We present a case report involving a farmer who visited the emergency department due to dyspnea.

\section{CASE REPORT}

A previously healthy, 66-year-old male patient presented to the emergency department (ED) for evaluation of progressive dyspnea, which had begun 3 months prior to presentation. His family and past medical history were not remarkable except for 


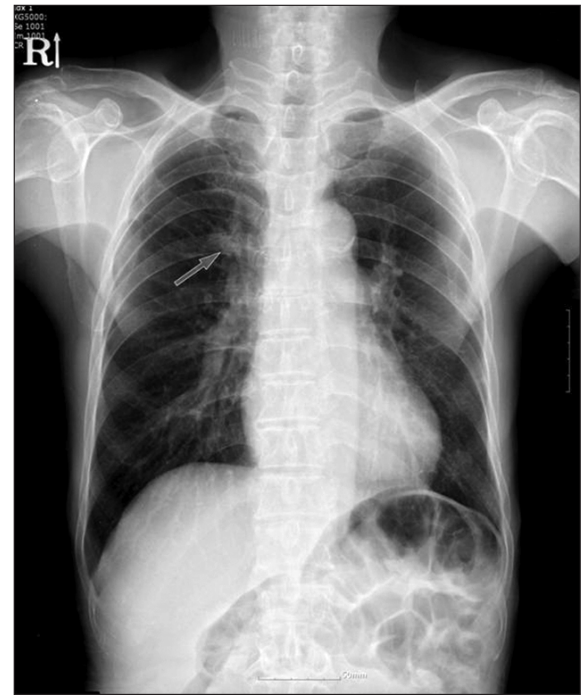

Figure 1. Chest X-ray. Right upper lung bronchopneumonia (arrow).

benign prostatic hyperplasia. He was a non-smoker and denied alcohol use. The patient denied any chest pain, rhinorrhea, cough, sputum production, or fever. The dyspnea was aggravated by exercise and relieved with rest. On examination, he was alert, but appeared thin, scaled and pale. His vital signs included a blood pressure of $143 / 73 \mathrm{~mm} \mathrm{Hg}$, heart rate of $84 / \mathrm{min}$, respiratory rate of $18 / \mathrm{min}$, temperature of $36.4^{\circ} \mathrm{C}$, and an oxygen saturation of $89 \%$ measured by pulse oximeter. The conjunctivae were pink. The lungs were clear to auscultation without wheezes, rales, or rhonchi. There was no abnormal heart sound or pitting edema at the ankles. The abdomen was flat and had normal bowel sound.

The initial laboratory evaluation showed an arterial blood gas of $\mathrm{pH} 7.347, \mathrm{PCO}_{2} 66.6 \mathrm{~mm} \mathrm{Hg}, \mathrm{PO}_{2} 63.3 \mathrm{~mm} \mathrm{Hg}$, and $\mathrm{HCO}^{3-}$ $31.3 \mathrm{mmol} / \mathrm{L}$. Point-of-care testing included creatine kinase 133 $\mathrm{IU} / \mathrm{L}$, creatine kinase-MB $6.8 \mathrm{ng} / \mathrm{mL}$, troponin-I $0.01 \mathrm{ng} / \mathrm{mL}$, B-type natriuretic peptide 12 , and D-dimer 0.03 . Blood chemistry analysis and complete blood count were normal. Influenza antigen test was negative. A chest radiograph showed atelectasis in the right upper lung field (Figure 1). Electrocardiography revealed right atrial enlargement and left ventricular hypertrophy with sinus rhythm (Figure 2).

Despite oxygen treatment with an 8-liter oxygen mask with reserved bag, the dyspnea became worse, and the oxygen saturation dropped to $86 \%$ after 3 hours. Computed tomography of the chest identified bronchiectasis in right upper lung field associated with bronchopneumonia (Figure 3). However, his

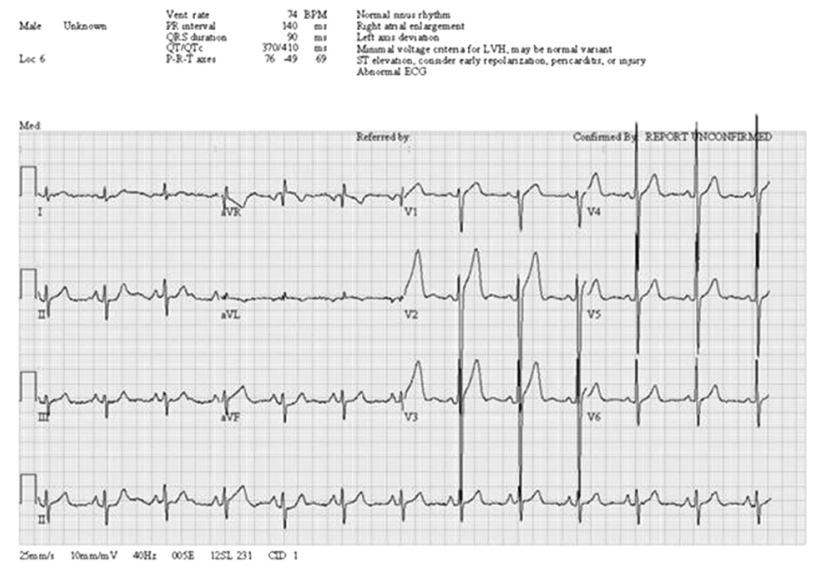

Figure 2. Electrocardiography.

symptoms were not entirely explained by this finding. A bedside echocardiogram revealed good left ventricular function (ejection fraction 56\%) and normal heart size without wall motion abnormality nor valvular problems.

The patient's history was reviewed, and the physical examination was repeated to look for additional information. The patient reported a $10 \mathrm{~kg}$ weight loss over the last year and had been bedridden for generalized weakness. The neurologic examination disclosed dysarthria, mild bilateral lower extremity weakness, and calf muscle atrophy. The dyspnea progressed to respiratory failure after 6 hours from the time of presentation in the emergency department, and intubation was required. Further investigations with nerve conduction study and electromyography demonstrated widespread denervation without any electrophysiologic abnormal findings of peripheral neuropathy. Finally, the patient was discharged with tracheostomy and home ventilator after several weeks' antibiotics treatment, and followed up via out-patient department.

\section{DISCUSSION}

MND refers to a group of diseases that affect the cells that control voluntary muscle activity. In the United States, MND is more commonly referred to as ALS or Lou Gehrig's disease (to avoid confusion, the annual scientific research conference dedicated to the study of MND is called the International ALS/ MND Symposium). ALS/MND refers to a specific subset of pathologically identical diseases. Forms of motor neuron disease 

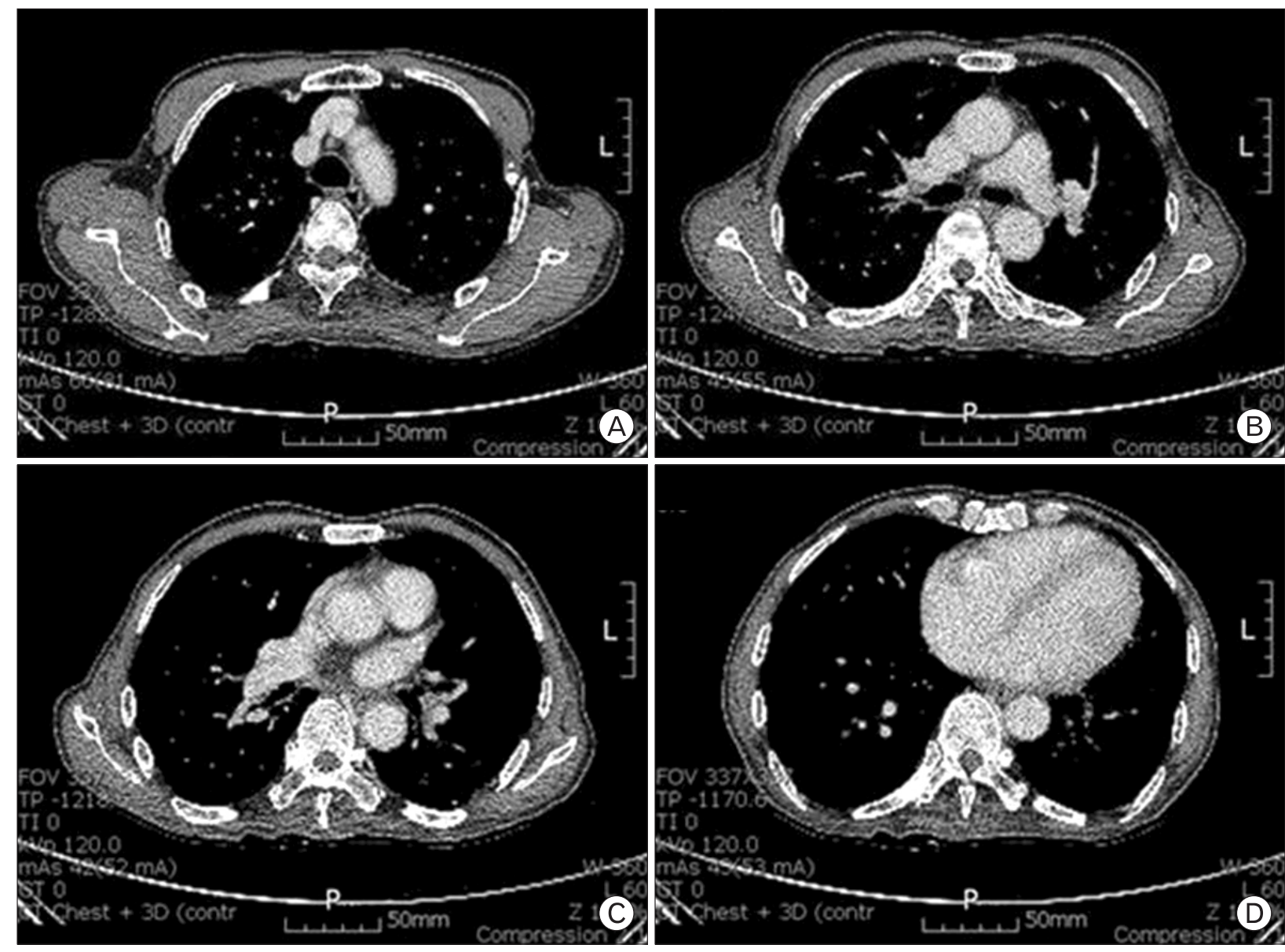

Figure 3. Enhanced chest computed tomography showed bronchiectasis with mucous plugging in right upper lobe. Otherwise, there was no remarkable finding.

include FALS, spinal muscular atrophy, bulbospinal muscular atrophy, anterior poliomyelitis, sporadic ALS, and primary lateral sclerosis. ${ }^{1)}$

Currently, no cures exist for MND. The only drug that affects the course of the disease is riluzole, which blocks the effect of the neurotransmitter glutamate. Riluzole generally extends the lifespan of an MND patient by a few months. ${ }^{2)}$ The lack of effective medications to slow the progression of MND does not imply that patients cannot be medically treated. Treatment focuses on the relief of symptoms associated with the disease as this case. A variety of health care professionals, including neurologists, speech-language pathologists, physical therapists, occupational therapists, dieticians, respiratory therapists, social workers, palliative care specialists, specialist nurses, and psychologists, are usually involved in the care of MND patients. ${ }^{1)}$

The incidence of MND is approximately 1 to 5 in 100,000 people, and men experience a slightly higher incidence than women. Symptoms usually present between the ages of 50 and 70 years, and include progressive weakness, muscle wasting, muscle fasciculation, spasticity or stiffness in the arms and legs, and overactive tendon reflexes. Neurologic examination identifies specific signs associated with upper and lower motor neuron degeneration. Signs of upper motor neuron damage include spasticity and brisk reflexes. Pathologic reflexes, including Hoffmann's sign in the fingers and the Babinski sign, are frequently seen. Signs of lower motor neuron damage include weakness, fasciculations, and muscle atrophy. These signs can occur in any muscle group, including the arms, legs, torso, and bulbar region. ${ }^{1)}$ In the vast majority of patients, limb weakness will occur within 1 to 2 years of the onset of bulbar symptoms. Swallowing difficulties and diaphragmatic weakness are usually late features. ${ }^{4)}$ 
Approximately 5\% of cases with MND present with respiratory weakness without significant limb or bulbar symptoms. ${ }^{4,5)}$ These patients present with symptoms of type 2 respiratory failure or nocturnal hypoventilation with dyspnea, orthopnea, disturbed sleep, morning headaches, and excessive day time somnolence. ${ }^{6}$ Yagyu et al. ${ }^{7)}$ and Czaplinski et al. ${ }^{8)}$ reported patients who had the motor neuron disease with respiratory failure as a primary manifestation, and visited ED. Similarly, our patient visited ED with respiratory failure as a presenting symptom, however motor weakness was developed before the respiratory symptom that was neglected and considered a part of the aging process by his family. The physicians in ED regarded the dyspnea as a manifestation of pneumonia, and the pathologic motor weakness as a general weakness from infection at first.

In conclusion, primary care physicians are often quick to conclude that motor power has weakened due to aging, only after usual history taking without cautious physical and neurologic examination. However, physicians who encounter patients with dyspnea in ED have to rule out pulmonary and cardiac dysfunction above all. If the clinical feature could not be explained, a differential diagnosis should be maintained, including neurologic disorders, which can frequently be overlooked in the elderly.

\section{CONFLICT OF INTEREST}

No potential conflict of interest relevant to this article was reported.

\section{REFERENCES}

1. Feldman EL, Goldman L, Ausiello DA. Amyotrophic lateral sclerosis and other motor neuron diseases. In: Cecil RL, Goldman L, Ausiello DA, editors. Cecil textbook of medicine. 22nd ed. Philadelphia: Saunders; 2004. p. 2316-9.

2. Miller RG, Mitchell JD, Lyon M, Moore DH. Riluzole for amyotrophic lateral sclerosis (ALS)/motor neuron disease (MND). Amyotroph Lateral Scler Other Motor Neuron Disord 2003;4:191-206.

3. Couratier P, Truong C, Khalil M, Deviere F, Vallat JM. Clinical features of flail arm syndrome. Muscle Nerve 2000;23:646-8.

4. de Carvalho M, Matias T, Coelho F, Evangelista T, Pinto A, Luis ML. Motor neuron disease presenting with respiratory failure. J Neurol Sci 1996;139 Suppl:117-22.

5. Chen R, Grand'Maison F, Strong MJ, Ramsay DA, Bolton CF. Motor neuron disease presenting as acute respiratory failure: a clinical and pathological study. J Neurol Neurosurg Psychiatry 1996;60:455-8.

6. Polkey MI, Lyall RA, Moxham J, Leigh PN. Respiratory aspects of neurological disease. J Neurol Neurosurg Psychiatry 1999;66:5-15.

7. Yagyu H, Kobayashi K, Kishi K, Kashiwahara K, Kiguchi T, Nakamura $H$, et al. Motor neuron disease with respiratory insufficiency as primary manifestation. Nihon Kokyuki Gakkai Zasshi 1999;37:321-6.

8. Czaplinski A, Strobel W, Gobbi C, Steck AJ, Fuhr P, Leppert D. Respiratory failure due to bilateral diaphragm palsy as an early manifestation of ALS. Med Sci Monit 2003;9:CS34-6. 